\title{
Urinary Biomarkers of Acute Kidney Injury in Patients With Liver Cirrhosis
}

\author{
Qasem Anass Ahmed ${ }^{1}$, Farag Salama El Sayed ${ }^{1}$, Hamed Emad ${ }^{1}$, Emara Mohamed ${ }^{2}$, Bihery \\ Ahmed ${ }^{2}$, Pasha Heba ${ }^{3}$
}

Internal Medicine Department , Faculty of Medicine, Zagazig University, Egypt ${ }^{1}$ Tropical Medicine Department , Faculty of Medicine, Zagazig University, Egypt ${ }^{2}$

Medical Biochemistry Department, Faculty of Medicine, Zagazig University, Egypt ${ }^{3}$

Correspondent author: Anass Ahmed Qasem, MD. Faculty Of Medicine-Zagazig University Zagazig. Egypt. Post Box: 45511. Tel: 00201001027353. E mail: chalenger46@gmail.com

\begin{abstract}
Background and aim: Acute kidney injury is a common complication in cirrhotic patients. Serum creatinine is a poor biomarker for detection of renal impairment in cirrhotic patients. The aim of this study was to evaluate Urinary Neutrophils Gelatinase-Associated Lipocalin (NGAL) and Urinary interleukin-18 (IL-18) as early biomarkers of acute kidney injury in cirrhotic patients. Patients and methods: 160 cirrhotic patients was enrolled in this study divided into 3 main groups according to presence or absence of ascites and renal impairment. Results: Significant elevation of both Urinary NGAL and Urinary IL-18 in cirrhotic patients with renal impairment especially in patients with Acute tubular necrosis (ATN) was observed. AUROC was (0.909) with (sensitivity 95.5\%, specificity 76.1) for Urinary NGAL and AUROC was (0.975), with (sensitivity $95.5 \%$, specificity $91.3 \%$ ) for Urinary IL-18. Conclusion : both Urinary NGAL and Urinary IL-18 can act as urinary biomarkers of acute kidney injury in cirrhotic patient

Key words : Cirrhosis, Acute kidney injury, NGAL, IL-18, Hepatorenal syndrome.
\end{abstract}

\section{INTRODUCTION}

Egypt was blessed with the river Nile and ancient culture but was deemed with liver diseases. Liver cirrhosis is a common disease in Egypt as Egypt has the highest incidence rate of HCV infection worldwide (1).

Acute kidney injury (AKI) in patients with cirrhosis is common. Up to $20 \%$ of hospitalized patients with cirrhosis develop AKI (2) and once AKI occurs there is a reported fourfold increased risk of mortality (3).

Typically, patients with decompensated liver cirrhosis have significant circulatory dysfunction which is characterized by a vasodilatory state, lower total peripheral resistance, activated renin-angiotensin-aldosterone system (RAAS) and finally renal arterial vasoconstriction (4).

In cirrhosis, AKI types include pre-renal azotemia, hepatorenal syndrome (HRS) and acute tubular necrosis (ATN) with prevalence rates of $68 \%, 25 \%$, and $33 \%$ respectively but their effect on mortality risk varies (2). Unfortunately these forms of AKI are difficult to distinguish clinically as serum creatinine $(\mathrm{sCr})$, the clinical standard to define kidney function, poorly discriminates AKI type in cirrhosis (5).

Furthermore, various factors can affect serum creatinine in cirrhotic patients such as age, gender, nutritional status, muscle mass, drug and volume distribution in addition deranged hepatic synthesis of the precursor (creatine) may contribute to impaired creatinine production in liver cirrhosis so utilization of serum creatinine con- centration for diagnosing renal dysfunction could be even more unsatisfactory (4).

Recently, in an effort to improve the definition of AKI and to highlight the importance of non-HRS kidney dysfunction in cirrhosis, the Acute Dialysis Quality Initiative (ADQI) and the International Ascites Club (IAC) jointly published a consensus statement regarding AKI classification (6), incorporating the Risk, Injury, Failure, Loss and End stage disease (RIFLE) and the Acute Kidney Injury Network (AKIN) guidelines. IAC definition of HRS (7) was classified as a specific form of AKI (8). Management of AKI in the setting of cirrhotic patients depends primarily on detection of the cause. HRS is treat ED pharmacologically whereas pre-renal azotemia is treated with plasma volume expansion which is not suitable in management of $\operatorname{ATN}(9,10)$. Neutrophils Gelatinase-Associated Lipocalin (NGAL) is a novel biomarker for diagnosing acute kidney injury (AKI). Several studies have demonstrated the utility of early NGAL measurements for predicting the severity and clinical outcomes of AKI $(11,12,13,14)$.

In fact, urine IL-18 has been shown to serve as an accurate biomarker to differentiate ATN from other etiological factors of renal disease (15). Moreover, the prognostic role of urine IL-18 has been validated in general patient groups admitted to ICU (16).

Therefore, The study was to assess the ability of urinary NGAL and IL-18 as early biomarkers of AKI in patients with cirrhosis. 


\section{PATIENTS AND METHODS}

\section{Study protocol}

This is a cross sectional study included 160 patients with cirrhosis admitted to the Liver Units in Zagazig university hospitals from July 2012 to December 2012 with history of follow up in outpatients clinics. The majority of patients were hospitalized for treatment of complications of cirrhosis. Exclusion criteria include: a) patients with hepatocellular carcinoma or cholangiocarcinoma; b) liver transplant patients; c) chronic kidney diseases patients maintained on regular hemodialysis before admission; and d) kidney transplant patients.

Study design was approved by institutional review board (IRB) of faculty of medicine, Zagazig university. Patients included in the study gave informed written consents in accordance with the Declaration of Helsinki.

Clinical and biochemical data were collected at the time of admission to Liver Units in Zagazig university hospitals with reference to previous patients data done in outpatient clinics. Child-Pugh Score and MELD score were calculated on admission $(17,18)$. Estimated GFR was calculated using MDRD equation (19). A fresh urine sample was taken to measure the urinary levels of sodium, creatinine, NGAL and IL-18. Venous blood samples were drawn from all participants, and sera were separated immediately.

\section{Classification of patients}

Patients were classified into three groups: a) non ascetic patients $(n=42)$; b) ascetic patients without renal impairment $(n=50)$, and $c)$ ascetic patients with renal impairment $(n=68)$.

This classification was used because it reflects the different stages of cirrhosis (20). Patients with renal impairment was further divided into four subgroups: a) pre-renal azotemia; b) Chronic kidney disease (CKD) (21); c) HRS (7); and d) ATN (22). The definitions for these different causes of renal impairment are shown in the Supplementary material

\section{Analytic procedures}

Urine samples for NGAL and IL-18 levels were immediately centrifuged, separated and stored at $-80^{\circ} \mathrm{C}$ until further analysis. Urinary NGAL was measured using NGAL ELISA kit (BioVendor GmbH, Germany) in relation to urinary creatinine. Urinary IL-18 was measured using a human IL-18 enzyme-linked immunosorbent assay kit (Medical and Biologic Laboratory, Nagoya, Japan) in relation to urinary creatinine.

Routine biochemical parameters were measured by calorimetric methods (Spinreact, SA Ctra, and Santa Coloma, Spain).

\section{Statistical analysis}

Results for continuous variables were expressed as mean \pm SD. Counts and percentages were used for the description of the categorical variables. Comparisons among groups were made with analysis of variance for continuous normal-distributed variables and with chi-squared test for categorical variables. Correlations were evaluated by means of the non-parametric Spearman's coefficient. The significance level for all statistical tests is set at 0.05 two-tailed. All statistical analyses were performed using SPSS V 19 software.

\section{RESULTS}

\section{Characteristics of the patient population}

The demographic, clinical data and biochemical parameters of all patients are shown in Table 1. Patients with renal impairment were divided into the four subgroups as show in Table 2.

\begin{tabular}{|c|c|c|c|c|}
\hline & $\begin{array}{l}\text { No ascites } \\
(\mathrm{n}=42)\end{array}$ & $\begin{array}{l}\text { Ascites without im- } \\
\text { pairment } \\
\text { of kidney function ( } \mathrm{n} \\
=50 \text { ) }\end{array}$ & $\begin{array}{l}\text { Ascites With impair- } \\
\text { ment of kidney function } \\
\qquad(\mathrm{n}=68)\end{array}$ & $\mathrm{P}$ \\
\hline Age (years) & $53.3 \pm 9.6$ & $54.04 \pm 11.03$ & $52.95 \pm 9.74$ & 0.85 \\
\hline Gender, male & $24(57 \%)$ & $30(60 \%)$ & $49(72 \%)$ & 0.21 \\
\hline Etiology of cirrhosis HCV/HBV/others & $32 / 7 / 3$ & $39 / 8 / 3$ & $54 / 10 / 4$ & 0.99 \\
\hline Hepatic encephalopathy, $\mathrm{n}(\%)$ & $6(14 \%)$ & $19(38 \%)$ & $32(47 \%)$ & 0.004 \\
\hline Gastrointestinal bleeding, n (\%) & $7(16 \%)$ & $13(26 \%)$ & $25(36 \%)$ & 0.173 \\
\hline Serum bilirubin(mg/dl) & $2.8 \pm 1.76$ & $4.4 \pm 2.6$ & $6.9 \pm 4$ & 0.0001 \\
\hline Serum albumin $(\mathrm{g} / \mathrm{l})$ & $31.5 \pm 6.1$ & $25.58 \pm 3.69$ & $27.72 \pm 5.61$ & 0.0001 \\
\hline Prothrombin time (\%) & $67.14 \pm 18.4$ & $58.18 \pm 8.84$ & $47.91 \pm 15.92$ & 0.0001 \\
\hline Serum creatinine $(\mathrm{mg} / \mathrm{dl})$ & $0.761 \pm 0.19$ & $1.045 \pm 0.26$ & $2.38 \pm 0.95$ & 0.0001 \\
\hline Glomerular filtration rate $\left(\mathrm{ml} / \mathrm{min} / 1.73 \mathrm{~m}^{2}\right)$ & $119.53 \pm 33.57$ & $85 \pm 21.87$ & $45.18 \pm 21.28$ & 0.0001 \\
\hline Serum sodium $(\mathrm{mEq} / \mathrm{L})$ & $135.26 \pm 3.8$ & $134.92 \pm 4.96$ & $131.72 \pm 6.46$ & 0.001 \\
\hline Serum potassium $(\mathrm{mEq} / \mathrm{L})$ & $3.979 \pm 0.42$ & $4 \pm 0.54$ & $4.39 \pm 0.78$ & 0.001 \\
\hline Child-Pugh score & $7.48 \pm 1.86$ & $9.86 \pm 1.22$ & $10 \pm 2$ & 0.0001 \\
\hline MELD score & $13.54 \pm 3.06$ & $16 . \pm 4.81$ & $25.74 \pm 7.76$ & 0.0001 \\
\hline Mean arterial pressure $(\mathrm{mmHg})$ & $83.76 \pm 13.9$ & $82.66 \pm 15.5$ & $77 \pm 14.8$ & 0.035 \\
\hline Urine sodium $(\mathrm{mEq} / \mathrm{L})$ & $49.71 \pm 34.5$ & $47.34 \pm 29.34$ & $36.6 \pm 21.27$ & 0.029 \\
\hline Urinary IL-18 ( $\mu \mathrm{g} / \mathrm{g}$ creatinine) & $254.5 \pm 77.9$ & $296.56 \pm 113$ & $983.48 \pm 594.43$ & 0.001 \\
\hline Urinary NGAL ( $\mu \mathrm{g} / \mathrm{g}$ creatinine) & $96.84 \pm 35.58$ & $113.76 \pm 47.98$ & $357.78 \pm 228.51$ & 0.001 \\
\hline
\end{tabular}

Table 1. Demographic, clinical and laboratory data of all patients. MELD: Model for End-Stage Liver Disease, NGAL: Neutrophil Gelatinase-Associated Lipocalin. Significant at: $\mathrm{P}<0.05 ; \mathrm{P}<0.01 ; \mathrm{P}<0.001$. 


\begin{tabular}{llllll}
\hline & $\begin{array}{l}\text { CKD } \\
(\mathrm{n}=15)\end{array}$ & $\begin{array}{l}\text { PRERENAL } \\
(\mathrm{n}=17)\end{array}$ & $\begin{array}{l}\text { HRS } \\
(\mathrm{n}=14)\end{array}$ & $\begin{array}{l}\text { ATN } \\
(\mathrm{n}=22)\end{array}$ & P \\
\hline Serum Creatinine $(\mathrm{mg} / \mathrm{dl})$ & $2.79 \pm 0.8$ & $1.76 \pm 0.2$ & $2.21 \pm 0.79$ & $2.7 \pm 1.23$ & 0.003 \\
\hline Sodium $(\mathrm{mEq} / \mathrm{L})$ & $132 \pm 6.71$ & $132 \pm 4.93$ & $129 \pm 5$ & $133 \pm 7.77$ & 0.257 \\
\hline Potassium $(\mathrm{mEq} / \mathrm{L})$ & $4.94 \pm 0.8$ & $4.39 \pm 0.61$ & $4.41 \pm 0.955$ & $4 \pm 0.54$ & 0.004 \\
\hline Glomerular filtration rate $(\mathrm{ml} / \mathrm{min} / 1.73 \mathrm{~m} 2)$ & $35.6 \pm 20.5$ & $53.2 \pm 13.84$ & $44.3 \pm 22.8$ & $45.98 \pm 47.48$ & 0.475 \\
\hline Mean arterial pressure $(\mathrm{mmHg})$ & $89.5 \pm 11.49$ & $77.2 \pm 14.2$ & $74.86 \pm 9.17$ & $69.78 \pm 15.35$ & 0.0001 \\
\hline Urine sodium $(\mathrm{mEq} / \mathrm{L})$ & $29.2 \pm 7.81$ & $29.3 \pm 13.18$ & $12.4 \pm 5.6$ & $62.68 \pm 8.17$ & 0.0001 \\
\hline Urinary $\mathrm{IL}-18(\mu \mathrm{g} / \mathrm{g}$ creatinine) & $582.34 \pm 98.24$ & $451.47 \pm 121.73$ & $953.5 \pm 273$ & $1687.1 \pm 447$ & 0.0001 \\
\hline Urinary NGAL $(\mu \mathrm{g} / \mathrm{g}$ creatinine) & $232.63 \pm 41.31$ & $161.15 \pm 60.75$ & $380.6 \pm 132.32$ & $580.51 \pm 238.75$ & 0.0001 \\
\hline Fractional excretion of sodium $(\mathrm{FeNa})(\%)$ & $0.32 \pm 0.17$ & $0.54 \pm 0.24$ & $0.15 \pm 0.07$ & $4.05 \pm 1.05$ & 0.0001 \\
\hline
\end{tabular}

Table 2. Characteristics of renal impairment patients CKD: Chronic Kidney Disease, HRS : Hepatorenal syndrome, ATN: acute tubular necrosis. Significant at: $\mathrm{P}<0.05 ; \mathrm{P}<0.01 ; \mathrm{P}<0.001$.

\begin{tabular}{lcccc}
\hline & \multicolumn{2}{c}{$\begin{array}{c}\text { Urinary NGAL } \\
(\mu \mathrm{g} / \mathrm{g} \text { creatinine })\end{array}$} & \multicolumn{2}{c}{$\begin{array}{c}\text { Urinary IL-18 } \\
(\mu \mathrm{g} / \mathrm{g} \text { creatinine })\end{array}$} \\
\hline & $\beta(\mathrm{r})$ & $\mathrm{p}$ & $\beta(\mathrm{r})$ & $\mathrm{P}$ \\
\hline Serum albumin $(\mathrm{g} / \mathrm{l})$ & 0.129 & 0.293 & 0.114 & 0.355 \\
\hline $\begin{array}{l}\text { Serum Creatinine }(\mathrm{mg} / \\
\mathrm{dl})\end{array}$ & 0.465 & $<0.001$ & 0.422 & $<0.001$ \\
\hline Serum bilirubin $(\mathrm{mg} / \mathrm{dl})$ & 0.1212 & 0.325 & 0.0502 & 0.668 \\
\hline $\begin{array}{l}\text { Urinary IL-18 }(\mu \mathrm{g} / \mathrm{g} \\
\text { creatinine) }\end{array}$ & 0.9 & $<0.001$ & & \\
\hline $\begin{array}{l}\text { Urinary NGAL }(\mu \mathrm{g} / \mathrm{g} \\
\text { creatinine) }\end{array}$ & & & 0.9 & $<0.001$ \\
\hline $\begin{array}{l}\text { Fractional excretion of } \\
\text { sodium (\%) }\end{array}$ & 0.687 & $<0.001$ & 0.807 & $<0.001$ \\
\hline $\begin{array}{l}\text { Mean arterial pressure } \\
\text { (mmHg) }\end{array}$ & 0.339 & 0.005 & 0.329 & 0.006 \\
\hline
\end{tabular}

Table 3. Simple linear regression of urinary IL-18 and urinary NGAL in renal impairment patients. $\beta$ : regression coefficient

\section{Urinary Neutrophil-gelatinase associated lipocalin (NGAL)}

Patients with renal impairment had higher urinary NGAL levels $(357.78 \pm 228.51 \mu \mathrm{g} / \mathrm{g}$ creatinine) compared to those of patients without renal impairment, either with or without ascites $(96.84 \pm 35.58,113.76 \pm 47.98 \mu \mathrm{g} / \mathrm{g}$ creatinine respectively).

The mean value of urinary NGAL in HRS (380.6 $\pm 132.32 \mu \mathrm{g} / \mathrm{g}$ creatinine) was significantly higher compared to pre-renal azotemia patients $(161.15 \pm 60.75 \mu \mathrm{g} / \mathrm{g}$ creatinine, $\mathrm{p}=0.0015)$ and significantly lower compared to ATN patients $(580.51 \pm 238.75, \mathrm{p}=0.0001)$ Furthermore Urinary NGAL levels in patients with CKD $(232.63 \pm 41.31$ $\mu \mathrm{g} / \mathrm{g}$ creatinine) were significantly different from those of patients with HRS ( $\mathrm{p}=0.003$ ) (Figure 1).

In simple regression analysis, urinary NGAL was positively correlated with serum creatinine $(r=0.465$, $\mathrm{p}<0.001)$, urinary IL-18 $(\mathrm{r}=0.9, \mathrm{p}<0.001)$, Fractional excretion of $\mathrm{Na}(\mathrm{FeNa})(\mathrm{r}=0.687, \mathrm{p}<0.001)$ and mean blood pressure $(\mathrm{r}=0.339, \mathrm{p}=0.005)$ in patients subgroups with renal impairment (Table 3 ).

The cut-off value of urinary NGAL that differentiate between patients with AKI and those with other causes of renal impairment was $286.3 \mu \mathrm{g} / \mathrm{g}$ creatinine (area under ROC curve is 0.909 ) with (sensitivity $95.5 \%$, specificity $76.1 \%$ ) with positive predictive value (PPV) of 65.6 and negative predictive value (NPV) of 99.2 (Figure 3).

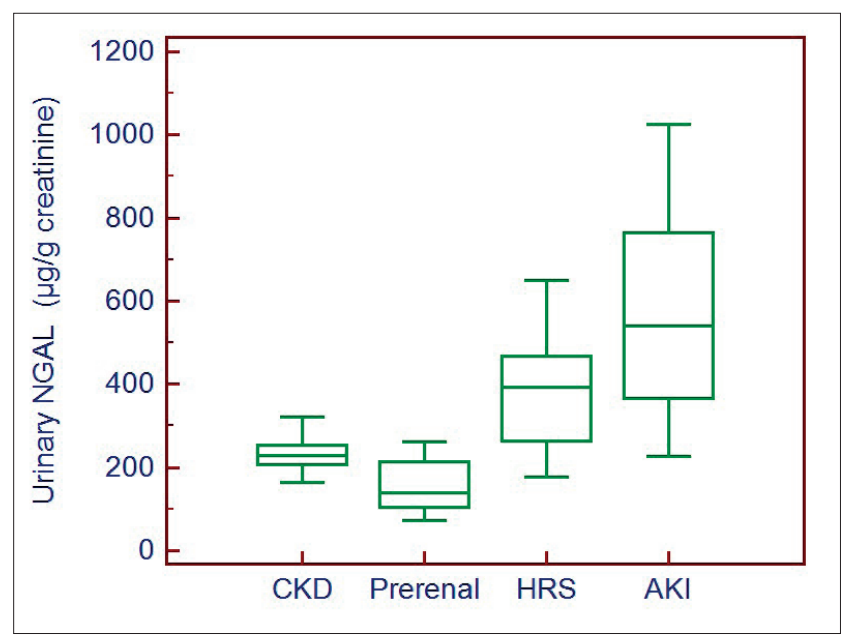

Figure 1. Box-plot of urinary NGAL levels according to the study subgroups of impairment of kidney function.

\section{Urinary Interleukin -18 (IL-18)}

Patients with renal impairment had higher urinary IL18 levels $(983 \pm 594 \mu \mathrm{g} / \mathrm{g}$ creatinine) compared to those of patients without renal impairment, either with or without ascites $(296.56 \pm 113,254.5 \pm 77.9 \mu \mathrm{g} / \mathrm{g}$ creatinine respectively).

Urinary IL-18 levels were analyzed in renal impairment patients' subgroups. We observed that Patients with ATN had the highest values of urinary IL-18, while patients with pre-renal azotemia had the lowest values $(1687 \pm 447$ vs. $451.47 \pm 121.73 \mu \mathrm{g} / \mathrm{g}$ creatinine, respectively; $\mathrm{p}=0.0001)$. Patients with HRS had intermediate values $(953 \pm 273 \mu \mathrm{g} / \mathrm{g}$ creatinine), which were significantly higher than those of patients with pre-renal azotemia $(\mathrm{p}=0.0015)$ and lower than those of patients with ATN $(\mathrm{p}=0.0001)$. Urinary IL-18 levels in patients with CKD $(582 \pm 98.24 \mu \mathrm{g} / \mathrm{g}$ creatinine) were significantly different from those of patients with HRS ( $\mathrm{p}=0.001$ ) (Figure 2).

In simple regression analysis, urinary IL-18 was positively correlated to serum creatinine $(\mathrm{r}=0.422, \mathrm{p}<0.001)$, FeNa $(r=0.807, \mathrm{p}<0.001)$ and mean blood pressure $(\mathrm{r}=$ $0.329, \mathrm{p}=.006))$ in patients subgroups with renal impairment (Table 3 ).

The cut-off value of urinary IL-18 that differentiate between patients with AKI and those with other causes of renal impairment was $1119.6 \mu \mathrm{g} / \mathrm{g}$ creatinine (area under 


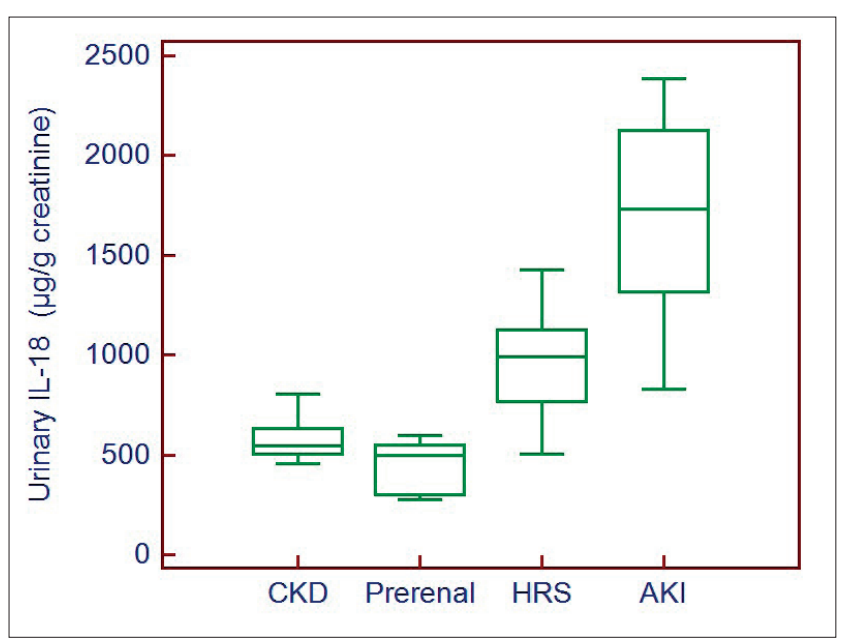

Figure 2. Box-plot of urinary IL-18 levels according to the study subgroups of impairment of kidney function.

ROC curve is 0.975 ), with (sensitivity $95.5 \%$, specificity 91.3 \%)with PPV of 84 and NPV of 99.3 (Figure 3).

\section{DISCUSSION}

AKI is a common condition in cirrhotic patients admitted to ICU. It is now recognized that AKI can significantly impact patients' outcomes (21). In fact, ATN is an important precipitating factor for the development of hepatorenal syndrome (HRS) $(2,18)$. It has been proposed that intense renal vasoconstriction in HRS, if prolonged, may lead to tubular ischemia and ultimately progress into $\operatorname{ATN}(24,25,26)$. Therefore, it may be difficult to distinguish HRS from ATN in clinical settings.

In general patients without liver cirrhosis, urine sediment and FeNa may help make the diagnosis of ATN. However, confounding results may be encountered in cirrhotic patients. Diamond et al. have shown that, in cirrhotic patients, FeNa may not correspond to the usual range for general patients with ATN (27). Therefore, FeNa is a less useful diagnostic tool for tubular injury in patients with advanced liver diseases, whose pre-existing hemodynamic states make them sodium-avid $(2,18,27,28)$.

Our study demonstrated a significant difference of Urinary NGAL and IL-18 in each category of AKI: highest in ATN, intermediate in HRS and low in pre-renal disease. Moreover, Urinary NGAL and IL-18 levels in patients with pre-renal azotemia were similar to those with normal kidney function and stable CKD. In contrast, sCr was not different between patients with ATN and HRS.

The mechanism by which patients with HRS have intermediate Urinary NGAL and IL-18 levels remains unclear. HRS physiology is thought to be an extreme pre-renal state $(29,30)$ with severe renovascular vasoconstriction and decreased GFR, but normal intrinsic kidney function. Kidney function can return to normal after improvement of hepatic hemodynamics $(29,30,31)$, or after renal transplantation into a recipient with normal hepatic function $(32,33)$.

However, pathologic investigations have reported subtle kidney tubular and glomerular damage in HRS kidneys, some seen only with electron microscopy $(24,34)$, perhaps resulting from the cellular changes associated with chronic activation of angiotensin-aldosterone signaling (35). It is conceivable that profound renovascular constriction

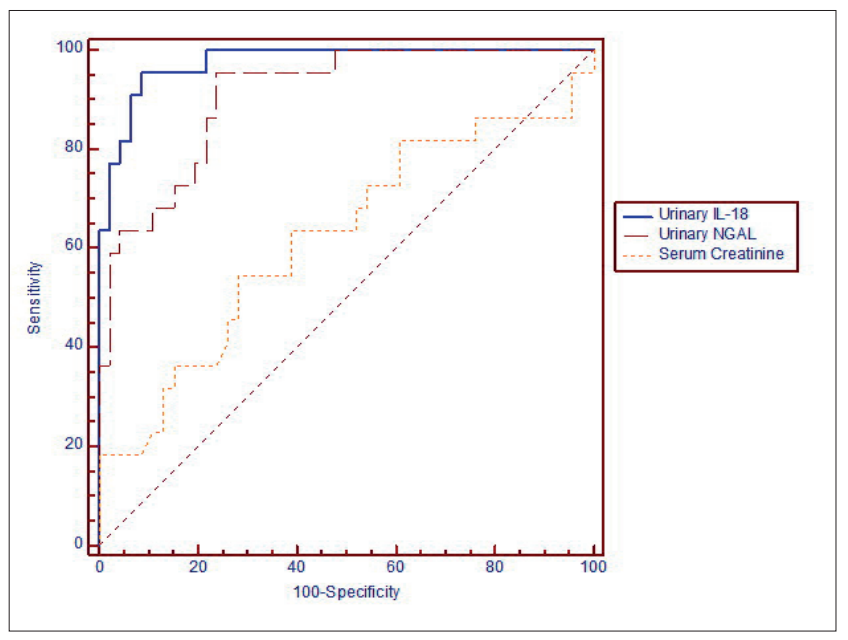

Figure 3. Receiver operating characteristic (ROC) curves to evaluate the capability of urinary IL-18, urinary NGAL and serum creatinine to diagnose acute tubular injury.

may cause sub-clinical tubular damage in at least a subset of nephrons, not detectable by urinary sodium, which is not sensitive enough to detect mild or patchy tubular epithelial damage. Our study also confirms previous studies demonstrating that a single Urinary NGAL or Urinary IL18 measurement on hospital admission has the potential to assist in determining type of kidney dysfunction, perhaps improving patient management and outcomes $(13,36,37)$. Urinary NGAL and Urinary IL-18 demonstrated an excellent discriminative power compared to serum creatinine (AUROC 0.909 for NGAL, 0.975 for IL-18, 0.622 for Cr) for discriminating ATN from HRS in our patients. This is in contrast to traditional measurements of kidney and liver disease severity including $\mathrm{sCr}$ and MELD score. Our data demonstrate that patients with cirrhosis are at a high risk for acute renal impairment (33.1\% of the patients, $41 \%$ of them diagnosed as ATN and $26.4 \%$ diagnosed as HRS).The present findings seem to be consistent with previous studies $(3,38)$ which confirm that non-HRS types of AKI are common in patients with cirrhosis and further studies are needed to determine inciting factors of AKI in this population. This study has some limitations. First, $\mathrm{sCr}$ inaccurately measures kidney function in cirrhosis $(5,39,40)$, and there is no widely available technique to accurately measure GFR in these patients. Second, Absence of kidney biopsy, which is rarely performed in this population, because of the high risk of complications and consequently lack a correlation between renal pathology and urinary NGAL and urinary IL-18.

\section{CONCLUSION}

Urinary NGAL and urinary IL-18 have the ability to differentiate between AKI types in patients with cirrhosis. This could improve risk stratification for patients admitted to the hospital with cirrhosis, perhaps leading to early ICU admission, transplant evaluation, prompt initiation of HRS therapy and early management of AKI. These findings, if confirmed in larger cohorts, could lead to the development of biomarker algorithms to rapidly identify patients with HRS and ATN and accurately predict prognosis.

\section{CONFLICT OF INTEREST: NONE DECLARED}




\section{REFERENCES}

1. El-Gafaary MM, Rekacewicz C, Abdel-Rahman AG, et al. Surveillance of acute hepatitis $\mathrm{C}$ in Cairo, Egypt. Journal of Medical Virology. 2005; 6: 520-525.

2. Garcia-Tsao G, Parikh CR, Viola A. Acute kidney injury in cirrhosis. Hepatology. 2008; 48: 2064-2077.

3. du Cheyron D, Bouchet B, Parienti JJ, et al. The attributable mortality of acute renal failure in critically ill patients with liver cirrhosis. Intensive Care Med. 2005; 31: 1693-1699.

4. Iwakiri Y, Groszmann RJ. The hyperdynamic circulation of chronic liver diseases: from the patient to the molecule. Hepatology. 2006; 43: S121-31.

5. Cholongitas E, Shusang V, Marelli L, et al. Review article: renal function assessment in cirrhosis-difficulties and alternative measurements. Aliment Pharmacol Ther. 2007; 26: 969-978.

6. Wong F, Nadim MK, Kellum JA , et al. Working Party proposal for a revised classification system of renal dysfunction in patients with cirrhosis. Gut. 2011; 60: 702-709.

7. Salerno F, Gerbes A, Gines P, et al. Diagnosis, prevention and treatment of hepatorenal syndrome in cirrhosis. Gut. 2007; 56: 1310-1318.

8. Bellomo R, Ronco C, Kellum JA, et al. Acute renal failure-definition, outcome measures, animal models, fluid therapy and information technology needs: the Second International Consensus Conference of the Acute Dialysis Quality Initiative (ADQI) Group. Crit Care. 2004; 8: R204-R212.

9. Mehta RL, Bouchard J. Controversies in acute kidney injury: effects of fluid overload on outcome. Contrib Nephrol, 2011; 174: 200-211.

10. Gines P, Angeli P, Lenz K, et al. EASL clinical practice guidelines on the management of ascites, spontaneous bacterial peritonitis, and hepatorenal syndrome in cirrhosis. J Hepatol. 2010; 53: 397-417.

11. Bachorzewska-Gajewska H, Malyszko J, Sitniewska E. et al. Neutrophils gelatinase-associated lipocalin and renal function after percutaneous coronary interventions. Am J Nephrol. 2006; 26: 287-292.

12. Makris K, Markou N, Evodia E. et al. Urinary neutrophils gelatinase-associated lipocalin (NGAL) as an early marker of acute kidney injury in critically ill multiple trauma patients. Clin Chem Lab Med. 2009; 47: 79-82.

13. Nickolas TL, O'Rourke MJ, Yang J, et al. Sensitivity and specificity of a single emergency department measurement of urinary neutrophils gelatinase-associated lipocalin for diagnosing acute kidney injury. Ann Intern Med. 2008; 148: 810-819.

14. Jeong TD, Kim S, Lee W, et al. Neutrophils gelatinase-associated lipocalin as an early biomarker of acute kidney injury in liver transplantation.Clin Transplant. 2012; 26: 775-781.

15. Parikh CR, Jani A, Melnikov VY, et al. Urinary interleukin-18 is a marker of human acute tubular necrosis. Am J Kidney Dis. 2004; 43: 405-414.

16. Parikh CR, Devarajan P. New biomarkers of acute kidney injury. Crit Care Med. 2008; 36: vS159-65.

17. Pugh RN, Murray-Lyon IM, Dawson JL, et al. Transection of the esophagus in the bleeding esophageal varices. Br J Surg 1973; 60: 648-652.

18. Moreau R, Lebrec D. Acute renal failure in patients with cirrhosis: perspective in the age of MELD. Hepatology. 2003; 37: 233-243.

19. Levey AS, Bosch JP, Lewis JB, et al. A more accurate method to estimate glomerular filtration rate from serum creatinine: a new prediction equation. Modification of Diet in Renal Disease Study Group. Ann Intern Med. 1999; 130; 6: 461-470.

20. Arroyo V, Terra C, Gines P. Advances in the pathogenesis and treatment of type- 1 and type-2 hepatorenal syndrome. J Hepatol, 2007; 46: 935-946.

21. Levey AS, Coresh J, Balk E, et al. National Kidney Foundation practice guidelines for chronic kidney disease: evaluation, classification, and stratification. Ann Intern Med. 2003; 139: 137-147.

22. Schrier RW. Diagnostic value of urinary sodium, chloride, urea, and flow. J Am Soc Nephrol. 2011; 22: 1610-1613.

23. Gines P, Martin PY, Niederberger M. Prognostic significance of renal dysfunction in cirrhosis. Kidney Int. 1997; 51: S77-S82.

24. Mandal AK, Lansing M, Fahmy A. Acute tubular necrosis in hepatorenal syndrome: an electron microscopy study. Am J Kidney Dis. 1982; 2: 363-374.

25. Rector WG Jr, Kanel GC, Rakela J, et al. Tubular dysfunction in the deeply jaundiced patient with hepatorenal syndrome. Hepatology. 1985; 5: 321-326.

26. Angeli P, Volpin R, Gerunda G, et al. Reversal of type 1 hepatorenal syndrome with the administration of midodrine and octreotide. Hepatology. 1999; 29: 1690-1697.

27. Diamond JR, Yoburn DC. Nonoliguric acute renal failure associated with a low fractional excretion of sodium. Ann. Intern. Med. 1982; 96: 597-600.

28. Esson ML, Schrier RW. Diagnosis and treatment of acute tubular necrosis. Ann Intern Med. 2002; 137: 744-452.

29. Ochs A, Rossle M, Haag K, et al. The transjugular intrahepatic portosystemic stent-shunt procedure for refractory ascites. N Engl J Med. 1995; 332: 1192-1197.

30. Iwatsuki S, Popovtzer MM, Corman JL, et al. Recovery from "hepatorenal syndrome" after orthotopic liver transplantation. N Engl J Med. 1973; 289: 1155-1159.

31. Cassinello C, Moreno E, Gozalo A, et al. Effects of orthotopic liver transplantation on vasoactive systems and renal function in patients with advanced liver cirrhosis. Dig Dis Sci. 2003; 48: 179-186.

32. McDonald FD, Brennan LA, Turcotte JG. Severe hypertension and elevated plasma renin activity following transplantation of "hepatorenal donor" kidneys into anephric recipients. Am J Med. 1973; 54: 39-43.

33. Koppel MH, Coburn JW, Mims MM, et al. Transplantation of cadaveric kidneys from patients with hepatorenal syndrome. Evidence for the functional nature of renal failure in advanced liver disease. N Engl J Med. 1969; 280: 1367-1371.

34. Kanel GC, Peters RL. Glomerular tubular reflux-a morphologic renal lesion associated with the hepatorenal syndrome. Hepatology. 1984; 4: 242-246.

35. Hollenberg NK. Aldosterone in the development and progression of renal injury. Kidney Int. 2004; 66: 1-9.

36. Siew ED, Ikizler TA, Gebretsadik T, et al. Elevated urinary IL-18 levels at the time of ICU admission predict adverse clinical outcomes. Clin J Am Soc Nephrol. 2010; 5: 1497-1505.

37. Devarajan P. Biomarkers for the early detection of acute kidney injury. Curr Opin Pediatr. 2011; 23: 194-200.

38. Elizabeth CV, Robert SB, Erica F , et al. Urinary Neutrophils Gelatinase-Associated Lipocalin Predicts Mortality and Identifies Acute Kidney Injury in Cirrhosis Dig Dis Sci. 2012: 57: 2362-2370.

39. Caregaro L, Menon F, Angeli P, et al. Limitations of serum creatinine level and creatinine clearance as filtration markers in cirrhosis. Arch Intern Med. 1994; 154: 201-205.

40. Papadakis MA, Arieff AI. Unpredictability of clinical evaluation of renal function in cirrhosis. Prospective study. Am J Med. 1987; 82: 945-952.

41. Levey AS, Coresh J, Greene T, et al. Expressing the modification of diet in renal disease study equation for estimating glomerular filtration rate with standardized serum creatinine values. Clin Chem. 2007; 53: 766-772.

42. Gill N, Nally Jr JV, Fatica RA. Renal failure secondary to acute tubular necrosis: epidemiology, diagnosis, and management. Chest. 2005; 128: 2847-2863. 